УДК 338.433 .4

08.00.00 Экономические науки

ЦЕЛЕСООБРАЗНОСТЬ ВЕДЕНИЯ УЧЕТА ПО
СИСТЕМЕ «ДИРЕКТ-КОСТИНГ» В
ОРГАНИЗАЦИИ АНЦ «РИС»
ТАХТАМУКАЙСКОГО РАЙОНА,
РЕСПУБЛИКИ АДЫГЕЯ

Губиева София Юрьевна

РИНЦ SPIN-код $=4819-1801$

РИНЦ Author ID $=818235$

студентка учетно-финансового факультета

Кубанский государственный аграрный

университет, Россия

В статье рассматривается целесообразность применения системы «директ-костинг» в российских организациях в целом, а также анализируется необходимость использования «директ-костинг» в АНТЦ «Рис», основной деятельностью которой является производство и реализация риса. Рассмотрим достоинства и недостатки использования данной системы, в контексте анализа деятельности АНТЦ «Рис»; раскроем сущность системы «директ-костинг». Кроме того, авторами была выдвинута необходимость представления характеристики организации учета затрат в целом и ее сравнение с методами ведения учета при использовании системы «директ-костинг». Доказана необходимость внедрения данной системы в организацию учета в российских организациях. С этой целью был проведен анализ изменения себестоимости риса при использовании системы «директ-костинг», была определена точка безубыточности, цена реализации и провизорная рентабельность. Все найденные показатели эффективности деятельности организации свидетельствуют о необходимости введения в АНТЦ «Рис» системы «директ-костинг». Учитывая возможность применения системы «директкостинг» параллельно с традиционной системой учета затрат, авторами дается характеристика оперативного управления производством и рентабельностью продаж, что позволяет полнее учесть рыночную конъюнктуру при ценообразовании и оценить вклад каждого подразделения организации АНТЦ «Рис» в целом, направленный на повышение эффективности производства риса

Ключевые слова: ДИРЕКТ-КОСТИНГ, ПЕРЕМЕННЫЕ ЗАТРАТЫ, ПОСТОЯННЫЕ ЗАТАРТЫ, КАЛЬКУЛИРОВАНИЕ, СЕБЕСТОИМОСТЬ

\section{Doi: 10.21515/1990-4665-130-004}

UDC 338.433.4

Economics

\section{FEASIBILITY OF ACCOUNTING IN THE «DIRECT-COSTING» SYSTEM IN ASTC «RIS» ORGANIZATION IN TAKHTAMUKAYSKY DISTRICT OF ADYGEYA}

\author{
Gubieva Sofia Yurievna \\ RSCI SPIN code $=4819-1801$ \\ RSCI Author ID $=818235$ \\ student of the Accounting and Finance Department \\ Kuban State Agrarian University, \\ Krasnodar, Russia
}

The expediency of the «direct-costing» system in Russian organizations as a whole is considered in the article, as well as the necessity of using direct-costing in the organization of the ASTC «RIS» with rice production and sale as main activity. The advantages and disadvantages of using this system in the context of the analysis of the ASTC «RIS» activities are considered; the essence of the system «direct costing» is revealed. Besides, the authors have extended the need of presenting the cost accounting organization characteristics in general and its comparison with methods of accounting in the use of «direct-costing». The necessity of the introduction of this system in accounting organization in the Russian organizations is proved. With this aim, an analysis was conducted of rice prime cost changes using the system of «directcosting»; the authors have determined the break-even point, selling price and provisory profitability. All the performance indicators of the organization show the need for the introduction of «direct-costing» system in ASTC «RIS». Considering the possibility of implementing the «direct-costing» system in parallel with the traditional cost accounting system, the authors give characteristics to operations management and selling profitability, that allows to be more responsive to market conditions in pricing and to assess the contribution of each division in the organization of ASTC «RIS» in general, aimed at improving the efficiency of rice production

Keywords: DIRECT-COSTING, VARIABLE EXPENSES, CONSTANT ACCOUNTS, CALCULATION, COST PRICE 
Современное общество вступило в фазу инновационной экономики, когда наибольшую значимость для развития любой страны приобретают информационное обеспечение и человеческий капитал.

Существующая в настоящее время система отечественного управленческого учета изобилует различными методами учета затрат и калькулирования себестоимости как российскими, так и заимствованными (зарубежными).

Перед руководством организации всегда стоит проблема выбора наиболее рационального в конкретных условиях метода учета затрат и калькулирования себестоимости. Весь мировой опыт свидетельствует об эффективности использования маржинального метода бухгалтерского учета - системы учета «директ-костинг» [1].

Сущность данной системы состоит в отнесении всех переменных затрат производства на готовую продукцию. Иначе говоря, себестоимость выпускаемой организацией продукции планируется и учитывается только в части переменных затрат, в то время как распределение всех постоянных затрат производства состоит в собирании последних на отдельных счетах бухгалтерского учета, не включаемых в калькуляцию и периодически списываемых на финансовые результаты.

По переменным расходам, которые составляют себестоимость продукции, оцениваются запасы, незавершенное производство и остатки готовой продукции на складе.

Необходимо отметить, что применение системы «директ-костинг» предполагает ведение дифференцированного учета общепроизводственных расходов, которые следует классифицировать на переменную и постоянную составляющие.

Использование системы «директ-костинг» в организации позволяет находить такие показатели как точка безубыточности, порог рентабельности, маржа безопасности и другие, что дает возможность 
прогнозировать доходы и расходы организации, используя инструменты моделирования и альтернативного выбора рациональных управленческих решений.

Внедрение данной системы кардинально меняет не только отечественную концепцию калькулирования, но и подходы к учету и расчету финансовых результатов [1].

Структура построения отчета о доходах и расходах в рамках системы «директ-костинг» несколько отличается от отчета о финансовых результатах и содержит операционную прибыль и маржинальный доход.

В отчет о доходах и расходах по системе «директ-костинг» включаются следующие показатели:

- выручка - важный составляющий компонент не только системы «директ-костинг», но и показателей результатов деятельности организации, во многом характеризующих ее эффективность;

- переменные затраты - затраты величина которых изменяется с изменением объемов выпускаемой продукции, основным признаком, определяющим данный вид затрат является их исчезновение при остановке производства;

- маржинальный доход - разность между выручкой от реализации и переменными затратами. Это часть выручки, формирующая прибыль и покрывающая постоянные затраты;

- постоянные затраты - затраты, которые не меняются с изменением объема производства, они связаны с постоянными издержками в каждый период времени;

- операционная прибыль - разность между нетто-выручкой, то есть выручкой за вычетом налогов, и расходами по обычным видам деятельности) [2];

Система учета «директ-костинг» позволяет: 
- упростить расчет себестоимости продукции, так как в ее состав включаются только производственные затраты;

- избегать трудоемких расчетов по распределению общехозяйственных расходов между видами выпускаемой продукции, то есть эти затраты относятся на уменьшение финансового результата;

- определить порог рентабельности, запас производственной и финансовой прочности, нижнюю границу цены продукции или заказа;

- сравнить рентабельность разных видов продукции;

- определить оптимальную программу выпуска и реализации продукции.

Рассмотрим преимущества и недостатки применения системы «директ-костинг» в условиях конкретной организации. Объектом исследования является Адыгейский научно-технический центр «Рис» (АНТЦ «Рис»), занимающийся производством и реализацией риса.

Основными преимуществами выбора системы калькулирования продукции по переменным издержкам являются:

1) непосредственное влияние на установление цены за единицу выпускаемой продукции, а также стимулирование производительности различных сегментов производственнофинансовой деятельности;

2) обеспечение возможности быстрого реагирования производства в контексте динамично меняющихся условий рынка;

3) проведение более эффективной политики ценообразования, создание наиболее выгодных комбинаций цены и объема;

4) организация простоты и объективности калькулирования усеченной себестоимости; 
5) появляется возможность обратить внимание руководства на процесс выявления продукции, характеризующейся большей рентабельностью; более четко контролировать процесс изменения маржинального дохода, как по организации в целом, так и по ее различным подразделениям [4].

Кроме того, при использовании системы «директ-костинг» в отчете о финансовых результатах выявляется изменение прибыли вследствие изменения переменных расходов, структуры выпускаемой продукции и цен реализации.

К недостаткам данной системы следует отнести следующее:

1) при формировании себестоимости выпускаемой продукции следует учитывать существование многих видов затрат, чья смысловая составляющая не может быть однозначно разделена на категории переменных или постоянных затрат;

2) при использовании системы «директ-костинг» уделяется мало внимания постоянным затратам;

3) зачастую при совокупном формировании затрат продукции происходит занижение, либо завышение стоимости ранее произведенной продукции, и, таким образом, образуется искажение финансового результата.

АНТЦ «Рис» использует попередельный-полуфабрикатный метод учета затрат, то есть затраты по производству риса и рисовой продукции учитываются по себестоимости каждого предыдущего передела и расходов по данному (текущему переделу).

В целях повышения эффективности производства риса и рисовой продукции, а также улучшения динамики показателя рентабельности реализуемой продукции для АНТЦ «Рис» мы рекомендуем совместить использование традиционного метода - попередельного-полуфабрикатного 
и системы учета исключительно переменных затрат в себестоимости продукции растениеводства (система «директ-костинг»).

АНТЦ «Рис» необходимо учитывать себестоимость всех предыдущих переделов, расходы по данному переделу, включая при этом в себестоимость производимой продукции только переменные затраты. Для реализации данного предложения АНТЦ «Рис» необходимо:

1) четко определить вид, учитываемых в себестоимости затрат в соответствии с их классификацией, что позволит лучше понять природу и источники формирования тех, или иных затрат. Для АНТЦ «Рис», например, необходимо произвести сбор всех видов затрат АНТЦ «Рис» - сортировку, сушку, уборку риса, затраты труда - и распределить их по видам затрат в соответствии с их классификацией;

2) учитывая затраты по каждому предыдущему переделу, руководство АНТЦ «Рис» должно контролировать конкурентоспособноть организации на рынке риса, по крайней мере в пределах, местности его нахождения.

Поэтому, завершив калькулирование различных сортов риса АНТЦ «Рис» необходимо соизмерить свои затраты с затратами других организаций, использующих методы учета затрат «директ-костинг» и попередельно-полуфабрикатный одновременно.

Реализуя обозначенные нами выше предложения, необходимо также тщательно проверить результаты классификации затрат в рамках отдельной организации (АНТЦ «Рис»), с целью избежать наиболее распространенных ошибок в управленческом учете АНТЦ «Рис». Среди типичных ошибок, выделяемых в российском бухгалтерском учете, находятся:

1) отсутствие системного подхода к разработке и внедрению новых методик учета и классификации затрат; 
2) непонимание важности аналитической функции системы бухгалтерского учета, и ориентация данной функции только на запросы внешних пользователей;

3) недостаточное знание методов классификации затрат (расходов или издержек) в управленческом учете, и с связи с этим практические трудности при разработке собственной классификации;

4) внедрение систем и методов по принципу «все сразу и сейчас» [5]. АНТЦ «Рис» необходимо избегать подобных ошибок. В частности связанных с методами классификации затрат. Это поможет избежать практических трудностей, организовать системность калькулирования затрат в центре и обеспечить оперативность управления производством. Оперативное управление производством состоит из целого комплекса работ по организации, в состав которых входят разработка и выполнение оперативно-календарных планов производства продукции, а также обеспечение рабочих мест всем необходимым, организация сменносуточных заданий на уровне цехов, рабочих мест и участков, контроль и регулирование хода производства.

Необходимо провести анализ учета затрат и калькулирования себестоимости продукции в организации. Для этого, приведем статьи затрат в АНТЦ «Рис» и сравним фактическую себестоимость продукции с себестоимостью по системе «директ-костинг».

В течение года записи по счету 20 «Основное производство» производятся нарастающими суммами, и отражаются в текущем учете развернуто. Статьи затрат в АНТЦ «Рис»: 1) материальные ресурсы, используемые в производстве; 2) семена и посадочный материал; 3) удобрения, используемые в АНТЦ «Рис»; 4) средства защиты растений от вредителей; 5) топливо и энергия на технологические цели; 6) работы и услуги сторонних организаций; 7) оплата труда (основная, 
дополнительная, натуральная, и другие выплаты, предусмотренные трудовым договором); 8) страховые взносы по фонду оплаты труда;

9) содержание основных средств (в статью включаются амортизация, затраты по ремонту основных средств); 10) прочие затраты (общехозяйственные расходы, общепроизводственные расходы и др.)

Согласно приведенным выше статьям затрат, отразим расходы АНТЦ «Рис», разделив их на условно-постоянные и условно-переменные. Составим соответствующие записи по счетам на основе фактов хозяйственной жизни центра.

Условно - переменные расходы:

1. Начислена заработная плата персоналу основного производства: Дебет субсчета 20-1 «Растениеводство» 1613 тыс. руб., Кредит счета 70 «Расчеты с персоналом по оплате руда»

1613 тыс. руб.;

2. Начислены взносы во внебюджетные фонды социальной защиты населения:

Дебет субсчета 20-1 «Растениеводство»

515 тыс. руб., Кредит счета 69 «Расчеты по социальному страхованию и обеспечению» 515 тыс. руб.;

3. Списана стоимость семян риса:

Дебет субсчета 20-1 «Растениеводство»

831тыс. руб., Кредит субсчета 10-1 «Семена и посадочный материал»

831тыс. руб.;

4. Списана стоимость минеральных и органических удобрений в основное производство:

Дебет субсчета 20-1 «Растениеводство»

720 тыс. руб., Кредит субсчета 10-2 «Минеральные и органические удобрения» 720 тыс. руб.;

5. Списаны химические средства защиты растений: 
Дебет субсчета 20-1 «Растениеводство»

640 тыс. руб.,

Кредит субсчета 10-3 «Химические средства защиты растений»

640 тыс. руб.;

6. Отражены затраты по содержанию основных средств:

a) начислена амортизация по основным средствам

Дебет субсчета 20-1 «Растениеводство»

143 тыс. руб., Кредит счета 02 «Амортизация основных средств» 143 тыс. руб.;

б) списана стоимость горюче-смазочных материалов

Дебет субсчета 20-1«Растениеводство»

Кредит субсчета $10-4$ «ГСМ»

445 тыс. руб., 445 тыс. руб.;

в) распределена стоимость ремонта основных средств

Дебет субсчета 20-1«Растениеводство»

49 тыс. руб.,

Кредит субсчета 23-1 «Ремонтные мастерские»

49 тыс. руб.;

Условно - постоянные расходы:

7. Распределена стоимость услуг и работ:

а) машинно-тракторного парка

Дебет субсчета 20-1 «Растениеводство»

7093 тыс. руб., Кредит субсчета 23-3 «Машинно-тракторный парк» 7093 тыс. руб.;

б) энергетического хозяйства

Дебет субсчета 20-1«Растениеводство»

105 тыс. руб., Кредит субсчета 23-5 «Энергетические производства» 105 тыс. руб.;

8. Распределены общехозяйственные расходы:

Дебет субсчета 20-1«Растениеводство»

520 тыс. руб.,

Кредит счета 26 «Общехозяйственные расходы»

520 тыс. руб.;

9. Отражены прочие расходы:

a) расчеты по налогам и сборам

Дебет субсчета 20-1 «Растениеводство»

424 тыс. руб.,

Кредит счета 68 «Расчеты по налогам и сборам»

424 тыс. руб.; 
б) расчеты с разными дебиторами и кредиторами

Дебет субсчета 20-1 «Растениеводство» 850 тыс. руб.,

Кредит счета 76 «Расчеты с разными дебиторами и кредиторами»

850 тыс. руб.

Размер фактической себестоимости риса, представлен в таблице 1. Таблица 1 - Расчет себестоимости 1 ц риса в ООО АНТЦ «Рис» Тахтамукайского района республики Адыгея, 2016 г.

\begin{tabular}{|l|c|c|c|}
\hline \multirow{2}{*}{ Вид продукции } & \multirow{2}{*}{$\begin{array}{c}\text { Количество произведенной } \\
\text { продукции, ц }\end{array}$} & \multicolumn{2}{|c|}{ Фактические затраты, руб. } \\
\cline { 3 - 4 } & 9300 & 605,59 & 5632000 \\
\hline Рис & на 1 ц & всего \\
\hline
\end{tabular}

Сравним размер фактической себестоимости в АНТЦ «Рис» с себестоимостью, определенной по системе «директ-костинг» и отразим алгоритм оприходования урожая риса на счетах бухгалтерского учета:

1. Отражена фактическая себестоимость производимой продукции, всего:

Дебет счета 43 «Готовая продукция» 5632 тыс. руб., Кредит субсчета 20-1 «Растениеводство» 5632 тыс. руб.;

2. Отражена себестоимость по системе «директ-костинг»:

Дебет счета 43 «Готовая продукция»

Кредит субсчета 20-1 «Растениеводство»
4956 тыс. руб., 4956 тыс. руб.

Расчет точки безубыточности представлен следующим равенством:

$$
\text { Тб = В - Пр - Пост р, где }
$$

В - выручка,

Пр - прибыль,

Пост р - постоянные расходы

$$
\text { Тб }=13948-4956-8992=0 ;
$$


Используя формулу точки безубыточности, рассчитаем стоимость минимального количества продукции на продажу, для определения нулевой прибыли:

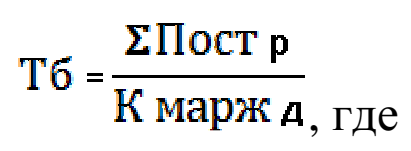

$\sum$ Пост $\mathrm{p}$ - сумма постоянных расходов,

К марж д - коэффициент маржинального дохода

$$
\text { Тб }=\frac{8992}{0,645}=13941 \text { тыс. руб.; }
$$

Т.e. для определения нулевой прибыли АНТЦ «Рис» необходимо продавать производимую продукцию на сумму 13941 тыс. руб.

Расчет средней цены реализации выглядит следующим образом:

$$
\text { Ц реализ }=\frac{B}{V} \text {, где }
$$

В - выручка,

$\mathrm{V}$ - объем реализованной продукции

Ц реализ $=\frac{13948000}{9300}=1500$ руб.;

Далее, рассчитаем сумму прибыли, используя в расчетах себестоимость по системе «директ-костинг» и сравним ее с прибылью, полученной за счет фактической себестоимости:

$$
\text { Пр } 1 \text { = В - Факт С - сть , где }
$$

Пр 1 - прибыль 1 ,

В - выручка,

Факт С-сть - фактическая себестоимость

$$
\begin{gathered}
\text { Пр } 1=13948-5632=8316 \text { тыс. руб.; } \\
\text { Пр } 2 \text { = В - С- сть по с"д- к" , где }
\end{gathered}
$$

Пр 2 - прибыль 2,

В - выручка, 
С-сть по с «Д-К»- себестоимость по системе «директ-костинг»

$$
\Pi \text { р } 2=13948-4956=8992 \text { тыс.руб. }
$$

Рассчитаем провизорную рентабельность, используя прибыль 1 и прибыль 2, сравним эти показатели:

$$
\mathrm{R} 1=\frac{\Pi p}{(\mathrm{cт-ть} \mathrm{OC+ст-ть} 06 \mathrm{cp}-\mathrm{B})} * 100 \% \text {, где }
$$

R1 - рентабельность 1 ,

Пр - прибыль,

ст-ть ОС - стоимость основных средств,

ст-ть Об ср-в - стоимость оборотных средств

$\mathrm{R} 1=\frac{8316}{6849} * 100 \%=121,4 \%$

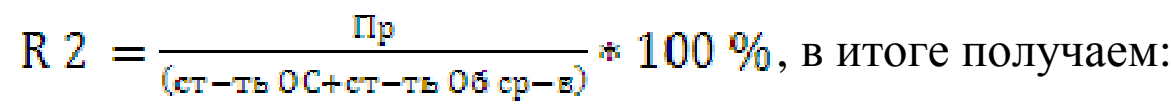

$\mathrm{R} 2=\frac{9992}{6849} \times 100 \%=131,3 \%$

Исходя из вышеприведенных расчетов, следует сделать вывод что АНТЦ «Рис» необходимо использовать систему «директ-костинг», поскольку использование данной системы позволяет повысить рентабельность производства риса.

Во многих зарубежных странах метод «директ-костинг» носит название - метод управления предприятием, иначе говоря, метод управления себестоимостью производимой продукции. Это обстоятельство подчеркивает тесную связь учета, анализа и принятия управленческих решений, ведь именно на основе данной системы строится система контроллинга.

АНТЦ «Рис» следует быстро подстраиваться под меняющиеся условия рынка, оперативно принимать решения по управлению затратами, оптимизировать виды (сорта) выпускаемой продукции (риса), а также грамотно принимать решения в следующих случаях: при возникновении 
вопросов замены старого оборудования на новое, при обнаружении проблем установления цен на новые виды (сорта) продукции, а также при возникновении сомнений целесообразности собственного производства [5].

Таким образом, АНТЦ «Рис» следует организовать более системный подход к классификации затрат, создать систему менеджмента, помогающую ориентироваться в условиях быстро меняющихся рыночных ситуаций, а также проанализировать метод внедрения в производство двух параллельно функционирующих методов учета затрат на производстве, а именно: системы «директ-костинг» и - попередельного-полуфабрикатного метода исчисления себестоимости производимой продукции.

\section{Список литературы:}

1. Керимов, В.Э. Современные системы и методы учета и анализа затрат в коммерческих организациях: учебное пособие. - М: Издательство Эксмо,2005. - 144 с.

2. Типичные ошибки в российском управленческом учете [Электронный pecypc] / статья // - Режим доступа: https://books.google.ru/books?

3. Внедрение метода «директ-костинг» в управление затратами основного производства сельскохозяйственных организаций [Электронный ресурс] / статья // Режим доступа: http://cyberleninka.ru/article/n/vnedrenie-metoda-direkt-kosting-vupravlenie-zatratami-osnovnogo-proizvodstva-selskohozyaystvennyh-organizatsiy

4. Преимущества и недостатки систем управления затратами [Электронный pecypc] / статья, студенческий научный форум // - Режим доступа: https://www.rae.ru/forum2012/327/3307

5. «Директ-костинг» как важнейшая подсистема управленческого учета [Электронный ресурс] / статья, // - Режим доступа: http://cyberleninka.ru/article/n/direktkosting-kak-vazhneyshaya-podsistema-upravlencheskogo-ucheta

\section{References:}

1. Typical mistakes in Russian management accounting [Jelektronnyj resurs] / stat'ja // - Rezhim dostupa: https://books.google.ru/books?

2. Introduction of the "direct-costing" method in managing the costs of agricultural organizations main production [Jelektronnyj resurs] / stat'ja // - Rezhim dostupa: http://cyberleninka.ru/article/n/vnedrenie-metoda-direkt-kosting-v-upravlenie-zatratamiosnovnogo-proizvodstva-selskohozyaystvennyh-organizatsiy

4. Advantages and disadvantages of cost management systems [Jelektronnyj resurs] / stat'ja, studencheskij nauchnyj forum // - Rezhim dostupa: https://www.rae.ru/forum2012/327/3307 
5. "Direct Costing" as the most important subsystem of management accounting [Jelektronnyj resurs] / stat'ja, // - Rezhim dostupa: http://cyberleninka.ru/article/n/direktkosting-kak-vazhneyshaya-podsistema-upravlencheskogo-ucheta 